\title{
Attitudes among older drivers towards medical assessment at renewal of driving license in Sweden
}

\author{
Birgitta Thorslund $^{1} \cdot$ Niklas Strand $^{1} \cdot$ Tania Dukic Willstrand $^{1}$
}

Received: 2 May 2016 / Accepted: 10 March 2017 /Published online: 21 March 2017

(C) The Author(s) 2017. This article is published with open access at SpringerLink.com

\begin{abstract}
Purpose The aim was to examine attitudes among older adults in Sweden as regards a possible legislation for medical assessment at license renewal depending on their health status (vision and hearing) and gender.

Methods A questionnaire study measuring attitudes towards medical assessments at license renewal and an examination of vision, hearing, and cognitive abilities was conducted by the Swedish National Road and Transport Research Institute. 109 participants older than 60 years participated in the study (58 women, $51 \mathrm{men})$. They were categorized into four groups according to their health status: (1) without any visual or hearing impairment, (2) visual impairment, (3) hearing impairment, and (4) visual and hearing impairment. All data collection was performed in a driving assessment situation.

Results The answers showed positive attitudes towards recurring vision test (94\% positive) and recurring medical assessments ( $93 \%$ positive). A majority wanted to include tests of visual acuity, contrast vision, and visual field. The most common choice was a starting point of 70 years and an interval of 2-3 years. Gender effects showing that woman were more positive towards some assessment and shorter time intervals between them was revealed. No significant effect of hearing or vision decline was found. Better results on cognitive tests was associated with positive attitudes towards medical testing. Conclusions The participants were positive towards medical assessments at license renewal, indicating that there is an
\end{abstract}

Birgitta Thorslund

birgitta.thorslund@vti.se

1 VTI, The Swedish National Road and Transport Research Institute, Linköping, Sweden acceptance in the population for such legislation. Even short intervals such as every two or three years were accepted.

Keywords Older drivers $\cdot$ License renewal $\cdot$ Medical testing . UFOV

\section{Introduction}

Medical problems that may affect driving often arise due to natural aging and may include declines in vision, hearing, and cognitive abilities. Vision is a general term that refers to several abilities, such as: visual acuity (the eyes' resolution), visual field (the entire field of vision seen at one moment), and contrast vision (ability to distinguish differences in colour and brightness). These abilities can be measured to predict whether or not someone is likely to drive a vehicle safely [1]. The effect of hearing loss on traffic safety has received little attention in the literature, and opinions diverge as to whether it increases risk. Compensatory strategies when driving, such as decreased driving speed and more frequent glances in the rear-view mirror, have been associated with hearing loss among older adults [2].

Cognitive impairments following natural aging also merit consideration, as driving is among the most complex and safety-critical tasks in today's society [3]. Traditional vision tests such as contrast sensitivity and visual acuity are increasingly being combined with tests that also capture cognitive aspects. One such test is the Useful Field of View (UFOV) test, which successfully predicts safe driving/driving performance [4-7] in older adults. Another cognitive test strongly associated with driving ability in relation to avoiding difficult traffic situations is the Trail Making Test $[8,9]$.

Because both visual and cognitive impairments may develop gradually, those affected may not perceive that their driving 
skill has deteriorated. This is an important argument in favour of regular medical assessment of drivers. A review of the literature treating measurable aspects of vision that are relevant to safe driving concluded that available and broadly used tests of visual acuity are insufficient to ensure safe driving and must be combined with other tests [1]. Contrast sensitivity, UFOV, and glare sensitivity tests emerged as strong candidates to complement visual acuity testing and, moreover, UFOV was suggested to be the best predictor of driving performance [1].

Looking at medical requirements worldwide for driver licensing reveals that in countries with compulsory requirements, the limits for visual acuity and visual field are quite similar, whereas the variation is greater for monocular vision, diplopia, and requirements for driver's license renewal [10]. In most European countries, vision testing requirements are introduced sometime between 45 and 70 years of age and recur at an interval of 1-5 years. Hearing and cognitive tests are less common or non-existing. For instance, Denmark recommends the so-called Clock drawing test, which can be used to screen for dementia and cognitive impairment, to determine fitness to drive for drivers aged 70 and older [10], and to our knowledge there is no country performing or recommending hearing tests. Sweden is one of six EU countries with no requirement for medical testing at driver's license renewal, the others being Austria, France, Great Britain, Hungary, and Germany [11]. In neighbouring countries Norway and Denmark, a medical testing certificate is required from 75 years of age, and in Finland an optical record is compulsory from 45 years of age.

A current debate in Sweden endorsed by the Swedish Transport Agency concerns whether periodic medical testing should be implemented for people starting at age 65 or 70 years to check their fitness to drive. There are many arguments in favour as well as some against this proposal. In some countries or states where medical and cognitive screening for older drivers has been introduced, there is a little evidence that such screening helps reduce injuries and fatalities on the road for this group $[12,13]$. Some studies have demonstrated a reverse effect in which more injuries occur among older drivers in countries or states where there is screening testing [14]. This finding is interesting, because the prevalence of some declines (i.e. contrast sensitivity and glare sensitivity) that are excluded from driving capability standards is higher than others that are included (i.e. visual acuity and visual field) [15]. declines not being included in standards for driving capability, contrast sensitivity and glare sensitivity, has been shown higher than others being included (visual acuity and visual field) Many countries require vision tests for older drivers at driver's license renewal, but fail to implement validated vision tests that can predict driving performance or to present the effects of these tests in terms of decreased accidents [16]. Thorslund and Strand suggest that available and broadly used tests of visual acuity should be combined with other tests [1]. It is therefore important to evaluate both which tests should be included in driving assessment and how these tests should be performed.

Factors associated with old age and having a negative impact on driving ability include impaired perceptual abilities, memory decline, reduced ability to sustain and switch attention, and mobility constraints [3]. However, aging is usually a gradual process, and while some skills deteriorate with increasing age, other more strategic skills are used more with increasing age [17]. As car drivers, older persons perceive certain driving situations and conditions as more demanding and potentially dangerous. These include driving in specific weather conditions, when feeling physically unwell or excited, in high-density traffic, on specific road types, and in response to others' driving behaviours $[18,19]$.

When travelling in a car, older men are more often drivers and women are more often passengers [20-24]. A common phenomenon is that women drive less as they age, finally ceasing driving because their husbands are the main drivers. Women are often discouraged by their husbands from driving and more often question their own driving abilities and skills $[22,24]$. Consequently, these drivers become dependent on their spouses' ability and health to accomplish daily and social activities. Previous research has demonstrated that older women cease driving when they consider themselves too old for driving, whereas men declare themselves to be safe drivers despite severe illness [25]. Women's reduced driving experience can result in a significant loss of mobility, increased dependency on transportation assistance, and increased vulnerability as unprotected road users. Gender differences in travel patterns might lead to gender differences in attitudes towards medical requirements and are worth studying specifically.

Introducing periodic vision tests does not necessary mean fewer older drivers. Shipp et al. [26] demonstrated that mandatory tests were not associated with a decreased proportion of older drivers, because some give up and others resume driving after testing. The present paper addresses a topic that has recently attracted considerable attention, namely, the introduction of medical requirements for driver's license renewal, by presenting older adults' experiences and attitudes towards these.

\section{Aim and research questions}

More knowledge of the target group's attitudes towards mandatory medical tests is needed in order to assess whether there is acceptance of testing legislation or whether measures are needed to build such acceptance before continuing with any policies or legislation. It is also important to consider the target group's perspective in order to design policies successfully. This paper accordingly examines attitudes among older adults 
in Sweden towards possible legislation requiring medical testing at driver's license renewal. To accomplish this, the following two research questions were posed:

RQ1: What are the attitudes of older persons towards mandatory medical tests for license renewal? Do the factors age, gender, and vision and hearing impairments influence these attitudes?

RQ2: From what age and at what frequency are mandatory medical tests for license renewal accepted by older persons? Do the factors age, gender, and vision and hearing impairments influence these attitudes?

\section{Methods}

A questionnaire study measuring attitudes towards medical assessment at driver's license renewal and towards examination of vision, hearing, and cognitive abilities was conducted by the Swedish National Road and Transport Research Institute (VTI). The data were collected in Stockholm at St. Erik Eye Hospital by trained optometrists.

\subsection{Participants}

In total, 109 adults (58 women, 51 men) over 60 years of age ( $M_{\mathrm{age}}=69.45$ years, age range: $60-87$ years) holding valid driver's licenses and residing in Stockholm county, Sweden were recruited through social media and hearing loss associations to participate in the study. The mean annual distance in kilometres driven by each participant was 7617.5 $(S D=13,985.3)$. The participants were categorized into four groups according to their hearing and vision abilities, as follows: normal hearing and normal vision (NHNV; 10 women, 13 men, $M_{\text {age }}=68.8$ years, age range: $60-83$ years), normal hearing and vision loss (NHVL; 20 women, 9 men, $M_{\text {age }}=68.1$ years, age range: $61-77$ years), hearing loss and normal vision (HLNV; 11 women, 11 men, $M_{\text {age }}=71.3$ years, age range: $62-87$ years), and hearing loss and vision loss (HLVL; 17 women, 18 men, $M_{\text {age }}=69.8$ years, age range: 60-85 years). See Table 1 for group distribution. During examination, participants were asked to wear corrective eyewear as applicable. All participants were allowed to choose either two cinema tickets or a flower gift card with a value of EUR 20 as compensation for participation.

\subsection{Measures}

Most measures included in this study were identified in our previous study as promising for predicting traffic safety [1]. Tests were performed on the participants and questions were asked about the relevance of each test to a driving assessment situation.

\subsubsection{Vision and hearing tests}

The vision tests identified in the literature as the most promising and feasible were carried out. Visual acuity and contrast sensitivity were tested on all participants using an EDTRS chart with $100 \%$ and $10 \%$ contrast levels. Visual field was tested using a Humphrey Field Analyzer and the Esterman test protocol [26, 27]. Pure tone audiometry at four frequencies (i.e. 500, 1000, 2000, and $4000 \mathrm{~Hz}$ ) was conducted according to WHO methodology [28]. To evaluate the effect of hearing aids, and because it provides a more ecologically valid measure of hearing ability than pure tone audiometry, speech-innoise testing was performed with and without hearing aids, using lists and methods from Magnusson et al. [29].

\subsubsection{Cognitive tests}

Participants were asked to complete a computer-based version (V7) of the Useful Field of View (UFOV®) test. Skills measured by UFOV are thought to be used during driving [30], and the test is thought to be indicative of accident risk in the older demographic $[31,32]$. This test was believed to provide a measure of differences in driving-related attentional skills. Participants were required to perform all three subtests that measure stimulus identification, divided attention, and selective attention, respectively.

All participants also completed the Trail Making Test (TMT), which assesses visual search, processing speed, and mental flexibility [33] and has displayed a strong association with driving ability [8]. TMT part A consists of numbermarked targets connected in numerical order and part B of targets, marked with both numbers and letters, connected in
Table 1 Gender distribution and mean age in each participant group: normal hearing and normal vision (NHNV), normal hearing and vision loss (NHVL), hearing loss and normal vision (HLNV), and hearing loss and vision loss (HLVL)

\begin{tabular}{lllll}
\hline Participants & NHNV $^{\mathrm{a}}$ & NHVL $^{\mathrm{b}}$ & HLNV $^{\mathrm{c}}$ & HLVL $^{\mathrm{d}}$ \\
\hline Men/women & $13 / 10$ & $9 / 20$ & $11 / 11$ & $18 / 17$ \\
Age, years, mean $(S D)$ & $68.8(5.3)$ & $68.1(4.3)$ & $71.3(5.6)$ & $69.8(5.4)$ \\
Age range, years & $60-83$ & $61-77$ & $62-87$ & $60-85$ \\
Annual mileage, km, & $8600.0(9819.4)$ & $7572.8(7643.0)$ & $6634.1(12,442.1)$ & $7627.1(20,344.2)$ \\
$\quad$ & & & & \\
\hline
\end{tabular}


a combined numerical and alphabetical order; the result is the time needed to complete the task.

\subsubsection{Questionnaire}

The questionnaire was administered by researchers from VTI. Attitudes, defined as feelings or emotions associated with certain topics, were measured and Likert-type scales were used for most of the items included in the study [34]. The items are presented below and will henceforth be referred to as Q1, Q2, etc. Regarding Q3, the participants performed the tests before responding to the items, so they knew what the tests were about.

Q1: Introducing mandatory vision tests for older drivers is a good idea.

Q2: The recurrent medical assessment of older drivers is a good idea.

Q3: Do you think that the following tests should be included in a medical assessment of older drivers? (Visual acuity, Contrast sensitivity, Visual field, Glare sensitivity, Audiogram, Speech in noise, UFOV, TMT)

Q4: At what age do you think that mandatory medical assessments should be introduced for older drivers?

Q5: How often do you think that recurrent medical assessments of older drivers should be conducted?

Q1 and Q2 were responded to by choosing one alternative on a five-point Likert-type scale $(1=$ fully agree, $2=$ partly agree, $3=$ neither agree nor disagree, $4=$ partly disagree, 5 = disagree). Q3 was answered by choosing one of four alternatives on a five-point scale $(1=$ yes, $2=$ possibly, 3 = doubtful, 4 = absolutely not). Q4 was answered by selecting one year in the range of 60-85 years and Q4 by choosing an interval of 1, 2, 3, 5, or 10 years. For Q4 and Q5, answering "no tests should be introduced" was also an option.

\subsection{Analysis}

A Pearson correlation coefficient was computed to assess the relationship between responses to the questionnaire items, the results of the included cognitive tests, and chronological age. Cohen [35] was used to guide the interpretation of the strength of significant correlations. To test whether there were statistically significant differences between the four groups in their questionnaire responses, a Kruskal-Wallis $H$ test was conducted. Finally, Mann-Whitney $U$ tests were conducted to test for statistically significant differences in responses between men and women.

All statistical analyses were performed using IBM SPSS Statistics (version 22) and 0.05 was chosen as the significance level.

\section{Results}

First, descriptive results are presented for all questionnaire items. This is followed by presentation of gender differences and group differences. Finally, correlations of the responses with cognitive tests and with age are presented.

\subsection{Distributions}

The questionnaire included five items (Q1-Q5) regarding tests related to licensing requirements for older drivers (e.g. vision and cognitive tests). When asked whether mandatory vision tests were a good idea (Q1), the respondents displayed positive attitudes towards the suggestion. The majority (70.6\%) responded that they fully agreed with the statement. The responses to Q2 concerning recurrent medical tests indicate positive attitudes like those towards Q1. The majority (65.1\%) responded that they fully agreed with the statement in Q2. See Fig. 1 for an overview of the distribution of responses to Q1 and Q2.

When asked about the inclusion of various tests in a mandatory medical assessment, the results indicate that most respondents wanted to include tests of visual acuity, contrast vision, and visual field. For tests of glare sensitivity, UFOV, and TMT, most participants responded on the positive side of the scale, as they either wanted or possibly wanted to include the tests. For the hearing tests, i.e. audiogram and speech in noise, the participants were more doubtful. For audiogram, most chose responses in the middle of the scale (i.e. possibly or doubtful), while for speech in noise, most chose responses on the negative side of the scale (i.e. doubtful or absolutely not). To summarize, the participants were sceptical regarding hearing-related tests, somewhat positive or neutral towards cognitive tests, and were inclined to include vision tests. Fig. 2 provides an overview of the responses.

Most participants (91.74\%) chose responses to Q4 indicating that mandatory medical tests should be introduced for drivers above 60 years of age. The most common choice was a starting age of 70 years $(M=70.87, M d n=70$, Mode $=70, S D=6.59$ ). When asked at what interval recurrent medical tests should be conducted (Q5), most chose intervals of between every two and every five years, with the most common answer being every three years (Fig. 3).

\subsection{Effects of gender}

Differences between men and women were examined using Mann-Whitney $U$ tests. The results indicate no detectable differences for Q1, Q2, and Q4 regarding the introduction of mandatory vision tests, recurrent medical tests, and the age at which tests should be introduced, respectively. For Q3, there was a significant difference between men and women concerning the visual acuity and audiogram tests, such that 
Fig. 1 Distribution of responses to Q1 and Q2

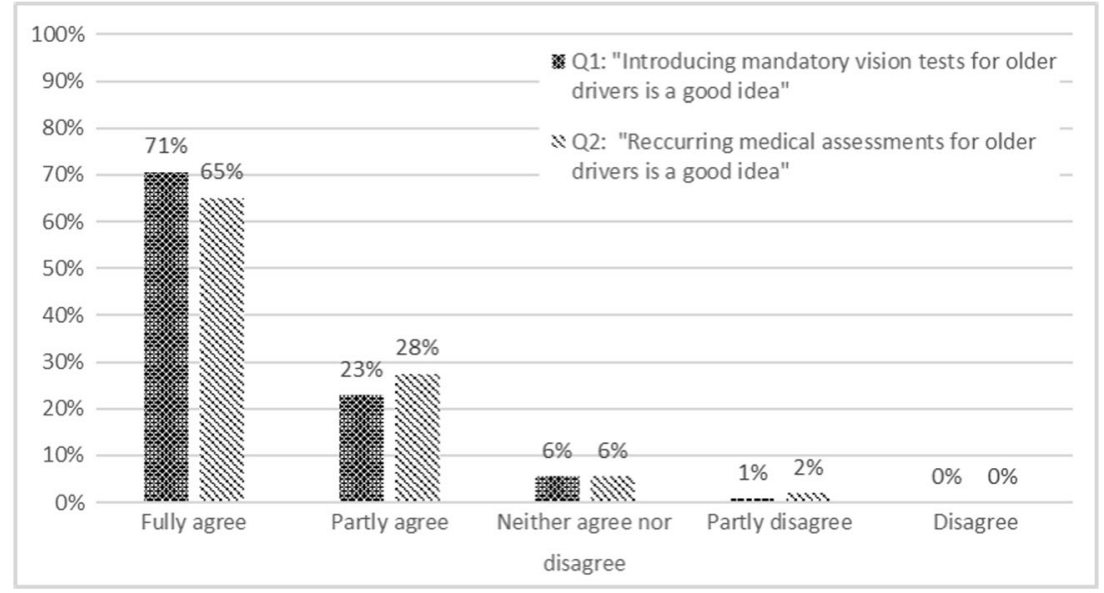

women were more positive towards their introduction. No detectable difference was found for the other tests. For Q5, concerning how often tests should be performed, there was also a detectable difference between men and women, with women thinking that tests should be performed more frequently. See Table 2 for an overview of the Mann-Whitney $U$ test results.

\subsection{Effects of group}

Kruskal-Wallis $H$ testing did not detect any significant differences between the responses to Q1, Q2, Q3, and Q5 between the four groups. Age-related decline in terms of hearing loss, vision loss, or combined hearing and vision loss did not affect the responses. Subjecting Q4 to Kruskal-Wallis $H$ testing revealed a significant difference between the four groups. Posthoc pairwise comparison detected differences between NHNV and HLNV $(p=0.015)$ and between NHNV and HLVL $(p=0.024)$. Post-hoc testing also indicated that NHVL and HLNV were close to being significant $(p=0.084)$. When $p$-values were adjusted to account for the number of comparisons, no differences remained significant. See Table 3 for an overview of the Kruskal-Wallis $H$ test results.

\subsection{Effects of cognitive ability}

When examining the questionnaire responses to find correlations with results on the cognitive tests, the results indicated that Trail Making Test B was slightly positively correlated with Q1 responses, concerning the introduction of mandatory vision tests for older persons $(r=0.216$, significant at the 0.05 level, two-tailed). This means that people performing better on Trail Making Test B were more inclined to agree to the introduction of mandatory vision tests. No correlation was found between Trail Making Test A and the three items.

For the other cognitive test, UFOV, there were correlations between the divided attention subtests and items regarding the implementation of vision testing ( $r=0.316$, significant at the 0.01 level, two-tailed) and recurrent testing ( $r=0.225$, significant at the 0.05 level, two-tailed). The correlation for implementing vision testing was medium-strength positive, while the correlation for recurrent testing was weakly positive. This implies that individuals performing better on these two subtests were more inclined to agree with the introduction of mandatory vision tests. For the selective attention subtest, there was a small positive correlation with how often
Fig. 2 Distribution of responses to Q3: "Do you think that the following tests should be included in a medical assessment of older drivers?"

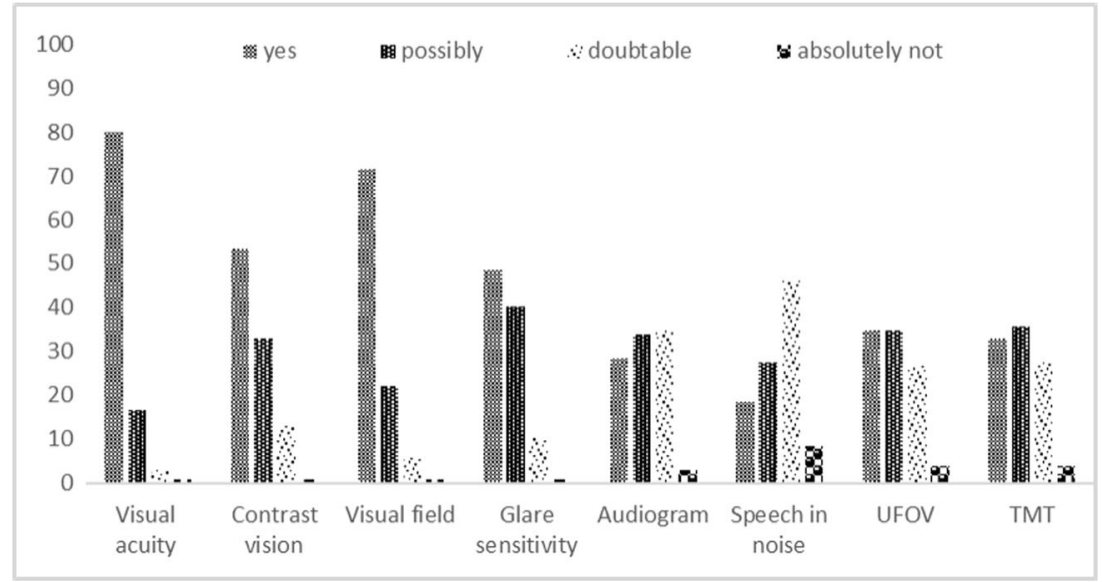


Fig. 3 Distribution of responses to Q5: "How often do you think that recurrent medical assessments of older drivers should be conducted?"

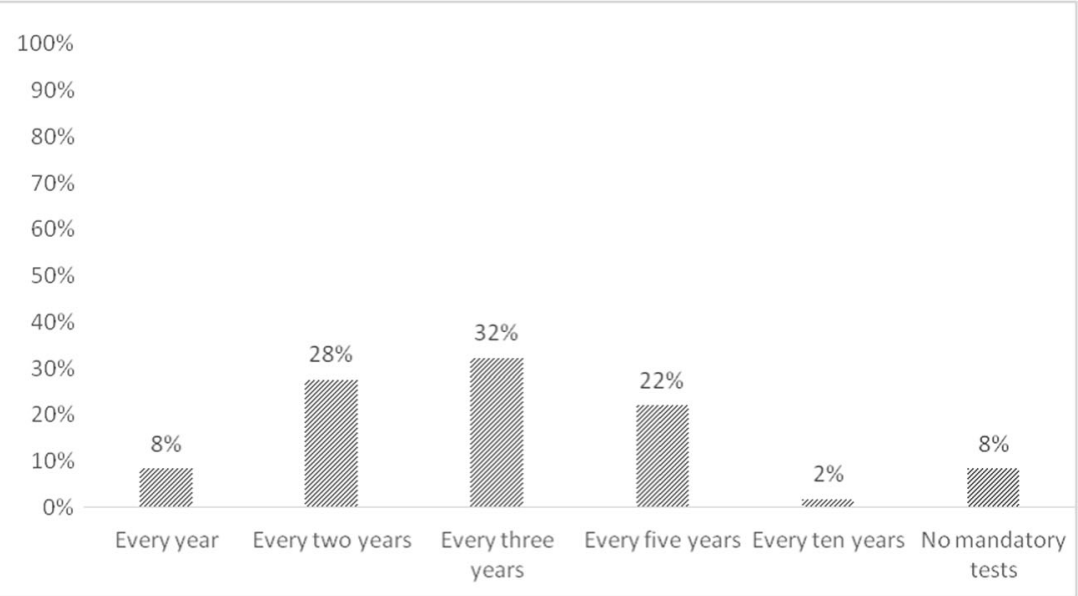

participants thought recurrent testing was justified ( $r=0.251$, significant at the 0.01 level, two-tailed). This means that individuals with better selective attention results suggested that testing should recur more often. There was no correlation between chronological age and the five items.

\section{Discussion}

The attitudes of older adults towards possible legislation requiring medical testing at driver's license renewal were examined using two main research questions:

RQ1: What are the attitudes of older persons towards mandatory medical tests for license renewal?

RQ2: From what age and at what frequency are mandatory medical tests for license renewal accepted by older persons?

Table 2 Results of Mann-Whitney $U$ tests of differences between women ${ }^{\mathbf{a}}$ and men $^{\mathbf{b}}$

\begin{tabular}{lll}
\hline Question & $U$-value & $P$ \\
\hline Q1 & 1529.0 & 0.703 \\
Q2 & 1567.5 & 0.521 \\
Q3 & & \\
$\quad$ Visual acuity & $1166.5 *$ & 0.007 \\
$\quad$ Contrast vision & 1328.0 & 0.309 \\
$\quad$ Visual field & 1339.0 & 0.281 \\
$\quad$ Glare sensitivity & 1378.0 & 0.498 \\
$\quad$ Audiogram & $1048.0 *$ & 0.006 \\
$\quad$ Speech in noise & 1196.0 & 0.066 \\
$\quad$ UFOV & 1605.5 & 0.417 \\
$\quad$ TMT & 1663.0 & 0.238 \\
Q4 & 1570.5 & 0.572 \\
Q5 & $1839.0 *$ & 0.024 \\
\hline a $n=58$ & & \\
b $n=51$ & & \\
$* p<0.05$ & &
\end{tabular}

These questions are discussed separately according to the present results and previous knowledge from the literature.

The attitudes towards medical assessment at driver's license renewal are extremely positive, with most respondents (i.e. $94 \%$ ) agreeing ( $71 \%$ fully and $23 \%$ partly) that this is a good idea. This implies that the respondents see the tests as providing evidence of driving ability, encouraging them to keep driving. This is in line with the suggestion that some might give up and others resume driving as a result of the testing, an interpretation of Shipp (2000), who demonstrated that mandatory tests were not associated with a decreased proportion of older drivers.

Regarding the type of tests to be included in recurrent medical assessments, the participants were sceptical towards hearing-related tests, somewhat positive or neutral towards cognitive tests, and inclined to include vision tests. Previous research is contradictory regarding the safety risks posed by hearing loss. In both simulator and field studies, hearing loss has been found to affect driving behaviour, mainly via compensatory strategies such as decreased driving speed and more comprehensive visual search behaviour [2]. Until we have a more definitive idea of how hearing loss impacts driving safety, it will probably not be emphasized when it comes to policy decisions about medical assessments for driving.

No correlation was found between chronological age and the five items, although there was correlation between some of the items and some parts of the cognitive testing, which in turn measures abilities that decline with increased chronological age.

Age-related ability declines, controlled for in this study, were not associated with attitudes, meaning that individuals with vision loss, hearing loss, or a combination of both were not more or less positive towards medical testing at license renewal. Cognitive abilities, on the other hand, which also decline with age, were correlated with attitudes, such that better results on the cognitive tests were associated with more positive attitudes towards medical testing at license renewal. There might be several reasons for this, both conscious and unconscious. One possibility is that individuals who are aware 
Table 3 Results of KruskalWallis $H$ testing of differences between the four groups: normal hearing and normal vision (NHNV), normal hearing and vision loss (NHVL), hearing loss and normal vision (HLNV), and hearing loss and vision loss (HLVL)

\begin{tabular}{|c|c|c|c|c|c|c|}
\hline \multirow[t]{2}{*}{ Question } & \multirow[t]{2}{*}{$X^{2}(3)$} & \multirow[t]{2}{*}{$p$} & \multicolumn{4}{|c|}{ Mean rank } \\
\hline & & & $\mathrm{NHNV}^{\mathrm{a}}$ & $\mathrm{NHVL}^{\mathrm{b}}$ & $\mathrm{HLNV}^{\mathrm{c}}$ & HLVL $^{d}$ \\
\hline Q1 & 1.997 & 0.573 & 51.43 & 53.03 & 53.61 & 59.84 \\
\hline Q2 & 1.528 & 0.676 & 49.96 & 53.67 & 57.00 & 58.16 \\
\hline \multicolumn{7}{|l|}{ Q3 } \\
\hline Visual acuity & 1.237 & 0.744 & 58.15 & 51.60 & 54.59 & 56.00 \\
\hline Contrast vision & 0.325 & 0.955 & 56.33 & 53.16 & 53.61 & 56.53 \\
\hline Visual field & 3.221 & 0.359 & 56.33 & 50.57 & 62.57 & 53.04 \\
\hline Glare sensitivity & 2.064 & 0.559 & 48.37 & 58.05 & 53.07 & 58.04 \\
\hline Audiogram & 2.824 & 0.419 & 55.96 & 47.21 & 57.93 & 58.99 \\
\hline Speech in noise & 5.634 & 0.131 & 52.87 & 49.26 & 49.55 & 64.59 \\
\hline UFOV & 5.175 & 0.159 & 49.91 & 46.97 & 60.41 & 61.60 \\
\hline TMT & 7.010 & 0.072 & 50.46 & 45.83 & 56.32 & 64.76 \\
\hline Q4 & $8.255^{*}$ & 0.041 & 42.43 & 49.83 & 65.05 & 61.23 \\
\hline Q5 & 0.817 & 0.845 & 53.35 & 52.88 & 60.07 & 54.66 \\
\hline \multicolumn{7}{|l|}{${ }^{\mathbf{a}} n=23$} \\
\hline \multicolumn{7}{|l|}{${ }^{\mathbf{b}} n=29$} \\
\hline \multicolumn{7}{|l|}{$\mathbf{c}_{n=22}$} \\
\hline \multicolumn{7}{|l|}{${ }^{\mathbf{d}} n=35$} \\
\hline$*_{p}<0.05$ & & & & & & \\
\hline
\end{tabular}

of their cognitive ability are more positive towards assessments if they have better cognitive skills and more negative if they have worse cognitive skills. People experiencing cognitive decline might be afraid of losing their driver's licenses. In addition, one cognitive ability associated with more positive attitudes towards medical assessment is mental flexibility, and better mental flexibility might make it easier to think outside one's own perspective and see the potential for increased traffic safety associated with such assessment.

The study revealed that the participating older adults accepted the introduction of medical assessments from the age of 60 years and at an interval of every 2-5 years in Sweden. This result is in line with requirements for vision tests in several other European Union member states, which start at ages of 45-70 years and recur at a 1-5-year interval.

A gender effect was found, such that the participating women were willing to accept a shorter interval for recurrent testing. Possibly, the women may be keener to prove their abilities in order to feel comfortable driving. This corresponds to previous research results suggesting that women may be discouraged by their husbands from driving and question their driving abilities more often than do men [22, 24].

The present results have important implications for policy decisions regarding testing implementation, as they suggest that older persons favour testing and are willing to accept it on a fairly regular basis. This implies that when policy decisions regarding such testing are introduced, the need for comprehensive information campaigns to persuade the target group can be expected to be low. In addition, only minor resistance and political opposition should be expected from the target group. However, as is customary, any policy decisions should be accompanied by adequate and relevant information for the target population.

Selection bias is possible in the present research, in that only a certain kind of person will enrol in a study of this kind, implying that the results should not be generalized to the older population as a whole at this stage. Several participants mentioned that they were happy to have a chance to participate and that they might need medical assessment. This motivation might have influenced the mainly positive attitudes towards the introduction of medical assessments seen in the results. Another shortcoming of this study was the relatively small sample size, so it is important to move forward with a larger study to gain more statistical power. Although the present results point in a certain direction, additional and larger studies are needed in order to draw more certain conclusions on the studied topic.

For the item regarding the suitable age at which to introduce medical assessments, the available response alternatives started at age 60 years, a starting point that might have affected the results. In Finland, for example, tests are introduced at age 45 years. One option would be to introduce a few tests relatively early, for example, at 45 years, and then to introduce additional tests with increasing age.

\section{Conclusions}

Regarding attitudes towards mandatory testing of the older population at driver's license renewal, the present results 
indicate that older persons are positive towards medical assessments, implying that there is acceptance in the population for such legislation. Furthermore, when determining a fair interval for such testing, our results indicate that a recommended interval of every two to five years is reasonable, even though a shorter interval, under every three years, is accepted by the majority.

Acknowledgements This study was funded by Promobilia, and Nordiskt Vägforum (NVF). We would also like to acknowledge Maria Nilsson and her students at Eyelab, Karolinska Institutet for a good collaboration with the data collection. We are also very grateful to St. Erik Eye Hospital for good collaboration during the data collection.

Open Access This article is distributed under the terms of the Creative Commons Attribution 4.0 International License (http:// creativecommons.org/licenses/by/4.0/), which permits unrestricted use, distribution, and reproduction in any medium, provided you give appropriate credit to the original author(s) and the source, provide a link to the Creative Commons license, and indicate if changes were made.

\section{References}

1. Thorslund B, Strand N (2016) Vision measurability and its impact on safe driving - a literature review. Submitted

2. Thorslund B (2014) Effects of hearing loss on traffic safety and mobility. Doctoral dissertation, Linköping: Linköping University Electronic Press

3. Groeger JA (2000) Understanding driving: applying cognitive psychology to a complex everyday task. Routledge, London

4. Johnson CA, Wilkinson ME (2010) Vision and driving: the United States. J Neuroophthalmol 30:170-176

5. Cushman LA (1996) Cognitive capacity and concurrent driving performance in older drivers. IATSS Res 20:38-45

6. Hoffman L, McDowd J, Atchley P, Dubinsky R (2015) The role of visual attention in predicting driving impairment in older adults. Psychol Aging 20(4):610-622

7. Myers R, Ball KK, Kalina TD, Roth DL, Goode KT (2000) Relation of useful field of view and other screening tests to onroad driving performance. Percept Mot Skills 91:279-290

8. Reger MA, Welsh RK, Watson GS, Cholerton B, Baker LD, Craft S (2004) The relationship between neuropsychological functioning and driving ability in dementia: a meta-analysis. Neuropsychology 18: 85-93

9. Rapoport MJ, Naglie G, Weegar K, Myers A, Cameron D, Crizzle A, Korner-Bitensky N, Tuokko H, Vrkljan B, Bédard M, Porter MM, Mazer B, Gélinas I, Man-Son-Hing M, Marshall S (2013) The relationship between cognitive performance, perceptions of driving comfort and abilities, and self-reported driving restrictions among healthy older drivers. Accid Anal Prev 61:288-295

10. Kørner EA, Lauritzen L, Mørkeberg Nilsson F, Lolk A, Christensen P (2012) Simple scoring of the clock-drawing test for dementia screening. Dan Med J 59(1):1-5

11. Bohensky M, Charlton J, Odell M, Keefe J (2008) Implications of vision testing for older driver licensing. Traffic Injury Prevention 9(4):304-313

12. Siren A, Haustein S (2015) Driving licences and medical screening in old age: review of literature and European licensing policies. Journal of Transport \& Health 2(1):68-78

13. Hakamies-Blomqvist L, Johansson K, Lundberg C (1996) Medical screening of older drivers as a traffic safety measure - a comparative Finnish-Swedish evaluation study. J Am Geriatr Soc 44(6):650-653
14. Langford J, Bohensky M, Koppel S, Newstead S (2008) Do older drivers pose a risk to other road users? Traffic Injury Prevention 9(3):181-189

15. Van Rijn LJ, Nischler C, Michael R, Heine C, Coeckelbergh T, Wilhelm H, Grabner G, Barraquer RI, Van den Berg TJ (2011) Prevalence of impairment of visual function in European drivers. Acta Ophthalmol 89:124-131

16. Desapriya E, Harjee R, Brubacher J, Chan H, Hewapathirane DS, Subzwari S, Pike I (2014) Vision screening of older drivers for preventing road traffic injuries and fatalities. Cochrane Database Syst Rev (2):CD006252. doi:10.1002/14651858.CD006252.pub4

17. Haustein S, Sirén A, Franke E, Pokrieke E, Alauzet A, MarinLamellet C, Armoogum J, O’Neill D (2013) Demographic change and transport. Final report of WP1:Consol

18. Jansen, E., Holte, H., Jung, C., Kahmann, V., Moritz, K., Rietz, C., Rudinger, G., \& Weidemann, C. (2001). Ältere Menschen im künftigen Sicherheitssystem Straße/Fahrzeug/Mensch [Senior citizens in the future safety system: street/vehicle/person] Bremerhaven: Wirtschaftsverlag NW.

19. Sullivan KA, Smith SS, Horswill MS, Lurie-Beck JK (2011) Older adults' safety perceptions of driving situations: towards a new driving self-regulation scale. Accid Anal Prev 43:1003-1009

20. Hanson TR, Hildebrand ED (2011) Can rural drivers meet their needs without a car? Stated adaptation responses from a GPS travel diary survey. Transportation 38:975-992

21. Li H, Raeside R, Chen T, McQuaid RW (2012) Population ageing, gender and the transportation system. Res Transp Econ 34:39-47

22. Rosenbloom S (2006b) Is the driving experience of older women changing? Safety and mobility consequences. Transp Res Rec 1956:127-132

23. Sirén A, Anund A, Sörensen G, Hakamies-Blomqvist L (2004) Förnuft och känsla: en narrativ studie om äldre kvinnors bilkörning (VTI notat 17). Väg och Transportforskningsinstitut, Linköping

24. Siren A, Hakamies-Blomqvist L (2006) Does gendered driving create gendered mobility? Community-related mobility in Finnish women and men aged 65+. Transport Res F: Traffic Psychol Behav 9:374-382

25. Fristedt S, Dahl AK, Wretstrand A, Björklund A, Falkmer T (2014) Changes in community mobility in older men and women. A 13year prospective study. PLoS One 9(2):e87827. doi:10.1371 /journal.pone.0087827

26. Shipp MD, Daum KM, Weaver JL, Nakagawara VB, Bailey IL, Wood GW, Maizel MB, Park WL (2000) Motor vision policy. Optometry 71:449-453

27. Crabb DP, Fitzke FW, Hitchings RA, Viswanathan RA (2004) A practical approach to measuring the visual field component of fitness to drive. Br J Ophthalmol 88:1191-1196

28. Arlinger S (ed) (2007) Nordisk Lärobok i Audiologi. Nordic Textbook of Audiology. C-A Tegnér AB, Bromma

29. Magnusson L, Karlsson M, Leijon A (2001) Predicted and measured speech recognition performance in noise with linear amplification. Ear Hear 22(1):46-57

30. Ball K, Owsley C (1993) The useful field of view test: a new technique for evaluating age-related declines in visual function. $\mathrm{J}$ Am Optom Assoc 64(1):71-79

31. Ball K, Owsley C, Sloane ME, Roenker DL, Bruni JR (1993) Visual-attention problems as a predictor of vehicle crashes in older drivers. Invest Ophthalmol Vis Sci 34(11):3110-3123

32. Owsley C, Ball K, McGwin G, Sloane ME, Roenker DL, White MF et al (1998) Visual processing impairment and risk of motor vehicle crash among older adults. Jama-Journal of the American Medical Association 279(14):1083-1088

33. Reitan R (1986) Trail making test. Manual for administration and scoring. Neuropsychological Laboratory, Tuscon

34. Likert R (1932) A technique for the measurement of attitudes. Archives of Psychology 22(140):1-55

35. Cohen J (1988) Statistical power analysis for the behavioural sciences, 2nd edn. Lawrence Erlbaum Associates, Hillsdale 